\title{
Anti-inflammatory effects of novel AP-1 and NF-kB inhibitors in dextran-sulfate-sodium-induced colitis in rats
}

\author{
MAGDY EL-SALHY $^{1-3}$ and KAZUO UMEZAWA ${ }^{4}$ \\ ${ }^{1}$ Division of Gastroenterology, Department of Medicine, Stord Helse-Fonna Hospital, 5416 Stord; ${ }^{2}$ Division of Gastroenterology, \\ Institute of Clinical Medicine, University of Bergen, 5020 Bergen; ${ }^{3}$ National Centre for Functional Gastrointestinal Disorders, \\ Department of Medicine, Haukeland University Hospital, 5021 Bergen, Norway; ${ }^{4}$ Department of Molecular Target Medicine, \\ Aichi Medical University School of Medicine, Nagakute, Aichi 480-1195, Japan
}

Received January 29, 2016; Accepted April 5, 2016

DOI: $10.3892 / \mathrm{ijmm} .2016 .2560$

\begin{abstract}
The aim of the present study was to elucidate the anti-inflammatory effects of the two novel antiinflammatory substances, 3-[(dodecylthiocarbonyl)-methyl]glutarimide (DTCM-G) and dehydroxymethylepoxyquinomicin (DHMEQ), on DSS-induced colitis in rats. For this purpose, rats with dextran sulfate sodium (DSS)-induced colitis were randomly divided into 3 groups with 10 animals in each group as follows: i) the control group, which received $0.5 \mathrm{ml}$ of $0.5 \%$ carboxymethyl cellulose (CMC; vehicle),ii) rats that received DTCM-G (20 mg/kg body weight in $0.5 \%$ CMC; the DTCM-G group), and iii) rats that received DHMEQ $(15 \mathrm{mg} / \mathrm{kg}$ body weight in $0.5 \% \mathrm{CMC}$; the DHMEQ group). The animals were sacrificed after the 5-day treatment period, and tissue samples were taken from their colons and sectioned for histological evaluation. The tissue sections were stained with hematoxylin and eosin, and immunostained for leukocytes, lymphocytes, macrophages/ monocytes and mast cells. The disease activity index (DAI), histological grading of colitis, and densities of several types of submucosal immune cells were compared between the controls, and the DTCM-G and DHMEQ groups. The DAI values were significantly lower in both the DTCM-G and DHMEQ groups than in the control group. The total scores for the histological grading of colitis were also significantly lower in the DTCM-G and DHMEQ groups than in the control group. The submucosal densities of leucocytes, lymphocytes, macrophages/monocytes and mast cells were significantly lower in the DTCM-G and DHMEQ groups than in the control group. Our findings indicate that the anti-inflammatory and anticancer effects of DTCM-G
\end{abstract}

Correspondence to: Professor Magdy El-Salhy, Division of Gastroenterology, Department of Medicine, Stord Helse-Fonna Hospital, Tysevegen 64, 5416 Stord, Norway

E-mail: magdy.el-salhy@helse-fonna.no

${ }^{*}$ Contributed equally

Key words: activator protein-1 inhibitor, nuclear factor- $\kappa \mathrm{B}$ inhibitor, rat, dextran sulfate sodium-induced colitis, immune cells, immunohistochemistry and DHMEQ, and the absence of any associated toxicity render them excellent therapeutic candidates for clinical use in the treatment of colitis.

\section{Introduction}

Inflammatory bowel disease (IBD) is a chronic and recurrent disorder with unknown etiology $(1,2)$. IBD occurs mostly in young individuals, interfering with their education, working abilities and social life (3). IBD comprises ulcerative colitis (UC) and Crohn's disease (CD), which have different clinical manifestations, courses and prognoses $(1,4,5)$. Their clinical courses can vary from frequent relapses or chronic active disease to years of virtually complete remission (3). IBD affects 1.4 million individuals in North America and 2.2 millions in Europe, and the reported incidence has a range of 3-20/100,000 individuals per year (6-8). Although the incidence of IBD is low in Asia compared with North America and Europe $(2,9,10)$, recent studies have indicated that the incidence of IBD in Asia is increasing $(2,10)$.

There is as yet no ideal treatment for IBD, and the treatment options available today comprise 5-aminosalicylates, corticosteroids, immunosuppressants such as thiopurine analogs, methotrexate and biological agents such as antibodies against tumor necrosis factor $\alpha$ (TNF $\alpha)(1,4,5,11-13)$. While 5 -aminosalicylates and corticosteroids are beneficial for many patients with IBD, they are not effective in the long term for most patients $(1,4,13)$, and the short- and long-term sideeffects of immunosuppressive drugs limit their use $(1,4,12)$. Furthermore, although anti-TNF $\alpha$ therapy can be effective in IBD, only approximately $65 \%$ of patients respond to this treatment $(3,11,12,14-20)$.

There are two novel potential therapeutic candidates for the treatment ofIBD:3-[(dodecylthiocarbonyl)-methyl]-glutarimide (DTCM-G) and dehydroxymethylepoxyquinomicin (DHMEQ). DTCM-G is a synthetic derivative of 9-methylstreptimidone isolated from Streptomyces spp. that has been shown to possess potent anti-inflammatory effects and found to inhibit the lipopolysaccharide-induced activation of macrophages, possibly via the suppression of activator protein-1 (AP-1) $(21,22)$. DHMEQ is a newly designed low-molecular-weight nuclear 
factor- $\kappa \mathrm{B}(\mathrm{NF}-\kappa \mathrm{B})$ inhibitor that has also demonstrated potent anti-inflammatory activity in many animal models $(23,24)$.

Animal models of IBD do not reproduce exactly the conditions in human IBD, but they are valuable for testing the efficacy of anti-inflammatory agents (25). Dextran sulfate sodium (DSS)-induced colitis has been considered to closely mimic the clinical and morphological features of human UC (25). The aim of this study was to elucidate the anti-inflammatory effects of the two novel anti-inflammatory substances, DTCM-G and DHMEQ, on DSS-induced colitis in rats.

\section{Materials and methods}

Rats. Male Wistar rats (Hannover GALAS; Taconic Farms, Lille Skensved, Denmark) with a mean body weight of $279.2 \mathrm{~g}$ (range, 228-382 g) were housed in Macrolon III cages with water and food available ad libitum. The standard diet provided to the rats (B\&K Universal, Nittedal, Norway) consisted of cereal products $(88.5 \%)$, soy protein $(6 \%)$, animal protein $(2.5 \%)$, soy oil $(0.5 \%)$, and vitamins, minerals and amino-acid supplements $(2.5 \%)$. The animals were maintained under a controlled environment at $21 \pm 1^{\circ} \mathrm{C}$, a relative humidity of $55 \pm 5 \%$ and under a 12/12 h light/dark cycle.

The study was carried out in accordance with the Directive for the Protection of Vertebrate Animals used for Experimental and Other Scientific Purposes of the European Union (86/609/EEC), in compliance with the Declaration of Helsinki. The local ethics committee for experimental animals approved the study protocols.

Study design. Thirty animals were allowed to acclimatize in the animal house under the aforementioned conditions for 7 days prior to the commencement of the experiments. Colitis was induced in these rats by the administration of DSS for 7 days (as described below). The animals were then randomized into 3 groups with 10 animals in each group according to the planned treatments, which were administered intraperitoneally (i.p.), twice daily for 5 days in all groups, as follows: i) the control group received $0.5 \mathrm{ml}$ of $0.5 \%$ carboxymethyl cellulose (CMC; vehicle), ii) the DTCM-G group received $20 \mathrm{mg} / \mathrm{kg}$ body weight DTCM-G in $0.5 \% \mathrm{CMC}$, and iii) the DHMEQ group received $15 \mathrm{mg} / \mathrm{kg}$ DHMEQ in $0.5 \% \mathrm{CMC}$. The methods used to synthesize DTCM-G and DHMEQ are described elsewhere $(21,26)$. At the end of the 5-day treatment period, the animals were sacrificed by $\mathrm{CO}_{2}$ inhalation, and a postmortem laparotomy was carried out in which the abdomen and colon were examined. Tissue samples were taken from the lower part of the colon for further, histological examination (Fig. 1).

Induction of colitis by DSS. Colitis was induced by the administration of DSS as previously described $(27,28)$. Briefly, the normal drinking water was replaced with distilled water containing 5\% DSS (mol. wt. 40 kD; TdB Consultancy, Uppsala, Sweden) for 7 days. The DSS solution was prepared daily, and the amount consumed by the rats was measured. The animals were monitored twice daily and were weighed on a daily basis. Animals with any signs of pain were injected subcutaneously with $1 \mathrm{ml}$ of Temgesic solution (containing $0.3 \mathrm{~g} / \mathrm{ml}$ Temgesic; Merck Pharmaceutical, Darmstadt, Germany).
The disease activity index (DAI). The DAI was used to measure the severity of the induced colitis. To this end, the animals were weighed, and the fecal consistency and presence and degree of occult or gross rectal bleeding were recorded daily. The DAI was determined (as described in detail elsewhere) $(29,30)$ by rating the percentage body weight loss $(0$, no body weight loss; $1,1-5 \% ; 2,6-10 \% ; 3,11-15 \% ; 4,16 \%)$, fecal consistency ( 0 , normal; 2 , loose; 4 , diarrhea) and the degree of rectal bleeding ( 0 , normal; 2 , occult bleeding; and 4 , gross bleeding). The DAI was estimated as the sum of all of these scores divided by 3 .

Histopathology and immunohistochemistry. The tissue samples taken from the colon during postmortem laparotomy were fixed overnight in $4 \%$ buffered paraformaldehyde, embedded in paraffin, and then cut into $5-\mu \mathrm{m}$-thick sections. The sections were deparaffinized and then stained with hematoxylin and eosin (H\&E) or else immunostained using the ultraView Universal DAB Detection kit (v1.02.0018) and the BenchMark Ultra IHC/ISH staining module (both from Venata Medical Systems, Basel, Switzerland). For immunostaining, the sections were incubated with one of the primary antibodies for $32 \mathrm{~min}$ at $37^{\circ} \mathrm{C}$. The primary antibodies used were monoclonal mouse antihuman CD45 (code no. M0701), monoclonal mouse antihuman CD47 (code no. I5647), monoclonal mouse antihuman CD68 (code no. M0814) and monoclonal mouse antihuman mast cell tryptase (code no. M7052) (all from Dako, Glostrup, Denmark). CD45 is considered as a common leukocyte antigen and is expressed exclusively on cells of the hematopoietic system and their progenitors. CD57 is expressed by subsets of natural killer cells and $\mathrm{CD} 8^{+}$lymphocytes, and by a small proportion of $\mathrm{CD}^{+} / \mathrm{CD} 45 \mathrm{R} 0^{+} \mathrm{T}$ lymphocytes. CD68 labels human monocytes, macrophages and myeloid cells. Human mast cell tryptases comprise a family of trypsin-like neutral serine proteases that are expressed predominantly in mast cells.

Histological grading of colitis. The histological grading of DSS-induced colitis was performed using the H\&E-stained sections by the same investigator (M.E.-S.) in a blinded manner as described previously (31). The following parameters were examined and graded: degree of inflammation $(0$, none; 1 , slight; 2 , moderate; 3 , severe), extent of inflammation ( 0 , none; 1 , mucosa; 2 , mucosa and submucosa; 3 , transmural), regeneration (4, no tissue repair; 3 , surface epithelium not intact; 2 , regeneration with crypt depletion; 1 , almost complete regeneration; 0 , complete regeneration or normal tissue), crypt damage ( 0 , none; 1 , basal one-third damaged; 2 , basal two-thirds damaged; 3 , only surface epithelium intact; 4, entire crypt and epithelium lost) and the percentage involvement $(1,1-25 \% ; 2$, $26-50 \% ; 3,1-75 \%$; 4, 76-100\%).

Quantification of immune cells. The immune cells were quantified by counting immunopositive cells in 10 randomly selected microscopic fields for each immunostained immune cell type (i.e., leukocytes, lymphocytes, macrophages/monocytes and mast cells). Measurements were performed on a computer linked to a microscope (BX 43) that was equipped with a digital camera (DP 26) (both from Olympus, Tokyo, Japan), and using Olympus cellSens imaging software (version 1.7). The number of immune cells in the submucosa of each field 


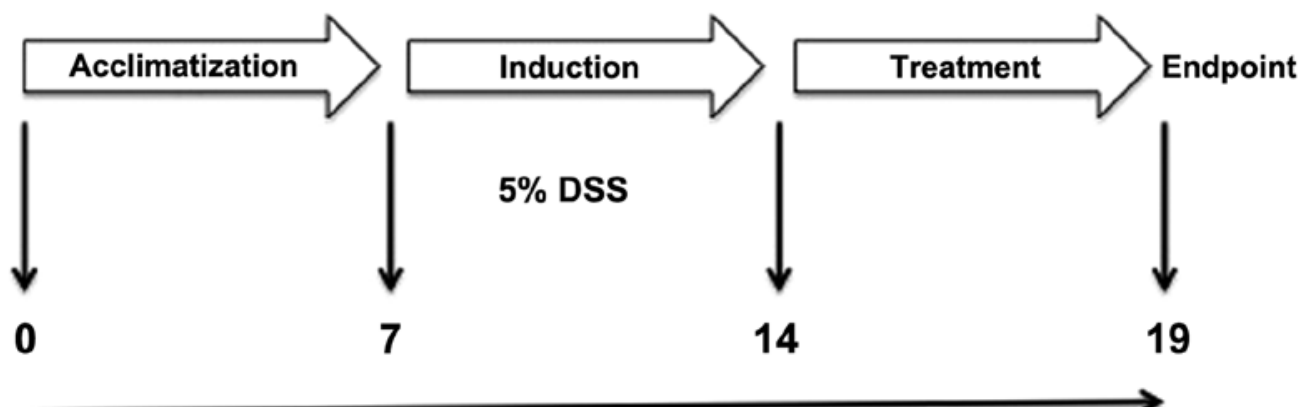

Figure 1. Overview of the experimental design.
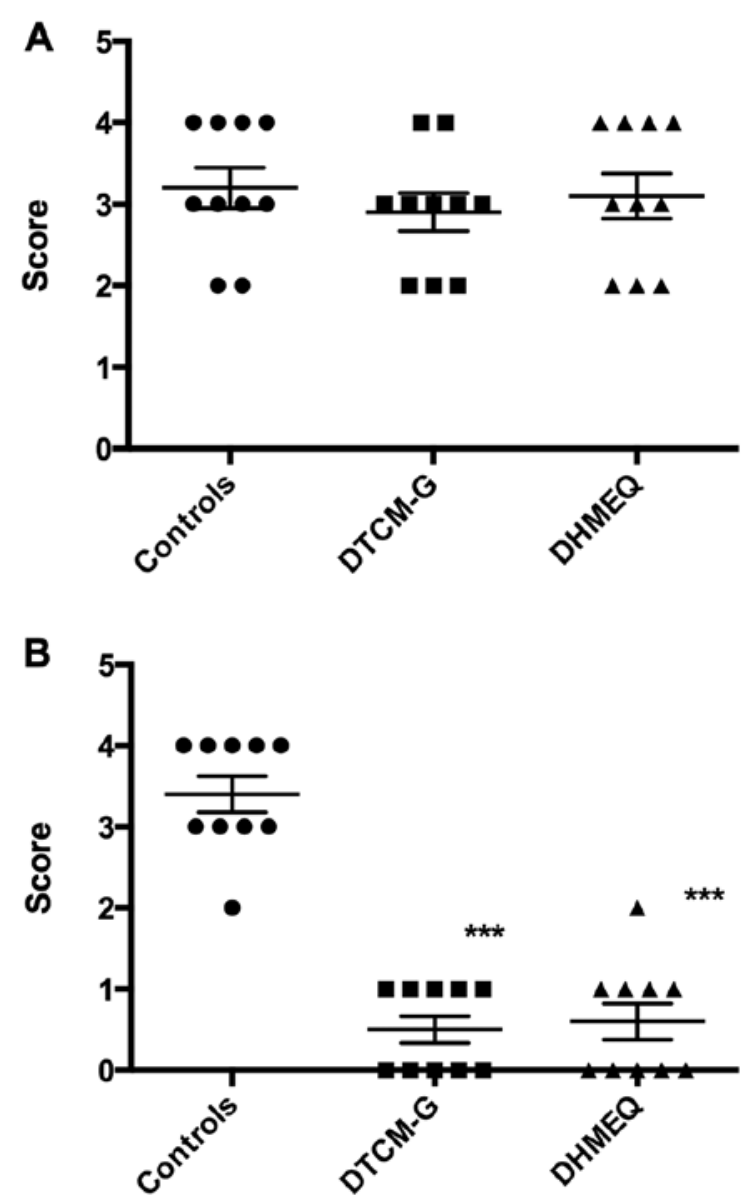

Figure 2. Disease activity index (DAI) values in the control, 3-[(dodecylthiocarbonyl)-methyl]-glutarimide (DTCM-G), and dehydroxymethylepoxyquinomicin (DHMEQ) groups (A) before and (B) after treatment. ${ }^{* * * *} \mathrm{P}<0.0001$ vs. controls.

was counted manually by pointing and clicking the computer mouse. A x40 objective was used, for which each frame (field) on the monitor represented a tissue area of $0.035 \mathrm{~mm}^{2}$. The data are presented as density measurements (i.e., the number of immune cells per field). Immunostained sections were coded and mixed, and measurements were made by the same investigator (M.E.-S.), who was blinded to the identity of the sections (i.e., the treatment group from which they were taken).

Statistical analysis. Differences between the control, DTCM-G and DHMEQ groups were tested using the Kruskal-Wallis non-parametric test, with Dunn's test as a post-test. The data are presented as the mean \pm SEM values, and the threshold for statistical significance was set at $\mathrm{P}<0.05$.

\section{Results}

$D A I$. The DAI values before treatment (i.e., at baseline) were $3.2 \pm 0.2,2.9 \pm 0.2$ and $3.1 \pm 0.3$ in the control, DTCM-G and DHMEQ groups, respectively; the baseline DAI did not differ significantly between the 3 groups ( $\mathrm{P}=0.7$; Fig. 2$)$. After the 5 days of treatment, the DAI values were significantly lower in the DTCM-G $(0.5 \pm 0.2)$ and DHMEQ $(0.6 \pm 0.2)$ groups than in the control group $(3.4 \pm 0.2 ; \mathrm{P}<0.0001$ for both).

Histological grading of colitis. At the endpoint of the experiment, histopathological examination of the colonic tissues revealed that the untreated control group had severe-tomoderate inflammation and disturbed mucosal architecture, crypt abscesses, edema, bleeding and infiltration of immune cells into the mucosa and submucosa. The only sign of inflammation observed in the animals treated with either DTCM-G or DHMEQ was a slight infiltration of immune cells into the submucosa (Fig. 3). The total scores for the histological grading of colitis were significantly lower in the DTCM-G (2.2 \pm 0.2$)$ and DHMEQ (2.8 \pm 0.4$)$ groups than in the control group (11.9 \pm 0.6 ; $\mathrm{P}<0.0001$ and $\mathrm{P}<0.001$, respectively) (Fig. 4).

Quantification of immune cells. The densities of submucosal leukocytes were $23.2 \pm 2.4,7.1 \pm 0.9$ and $5.9 \pm 0.8$ cells/field in the control, DTCM-G and DHMEQ groups, respectively (Kruskal-Wallis test was significant at $\mathrm{P}<0.0001$ ) (Figs. 5 and 6). The densities of submucosal leukocytes were significantly lower in the DTCM-G and DHMEQ groups than in the control group $(\mathrm{P}<0.001$ and $<0.0001$, respectively).

The densities of submucosal lymphocytes were $26.2 \pm 3.1$, $8.1 \pm 1.2$ and $7.8 \pm 0.8$ cells/field in the control, DTCM-G and DHMEQ groups, respectively (Kruskal-Wallis multiple comparison test was significant at $\mathrm{P}<0.0001$ ) (Figs. 5 and 7). The density of lymphocytes was significantly lower in the submucosa of the DTCM-G- and DHMEQ-treated animals than in their vehicle-treated, control counterparts $(\mathrm{P}<0.0001$ for both).

The submucosal densities of macrophages/monocytes in the control, DTCM-G and DHMEQ groups were 21.8 $\pm 2.2,6.4 \pm 0.9$ and $6.9 \pm 0.4$ cells/field, respectively (Figs. 5 and 8) (Kruskal- 

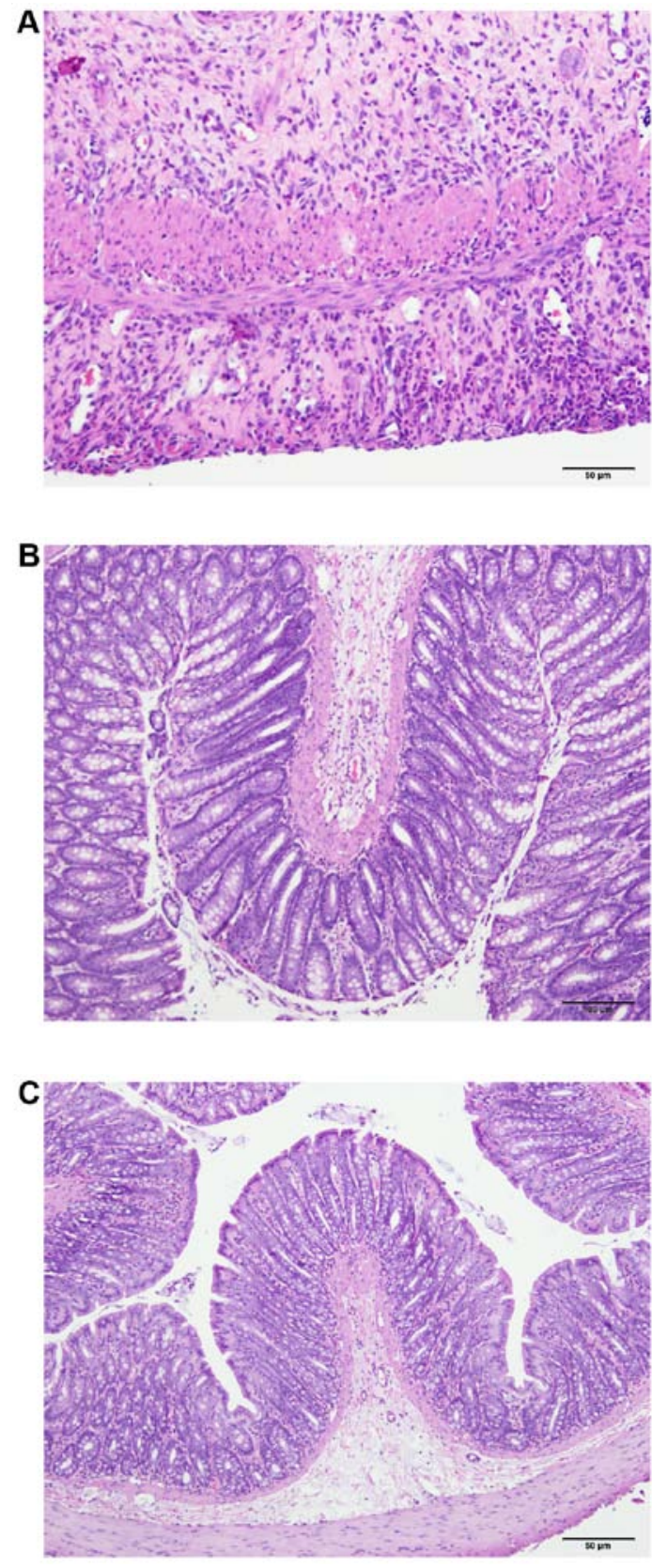

Figure 3. Histological appearances of the colon in (A) a control rat, (B) a 3-[(dodecylthiocarbonyl)-methyl]-glutarimide (DTCM-G)-treated rat, and (C) a dehydroxymethylepoxyquinomicin (DHMEQ)-treated rat.

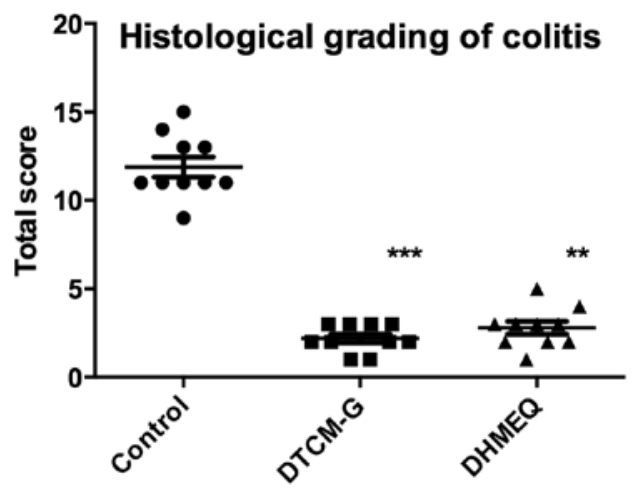

Figure 4. Total scores of histological grading for colitis in the control,3-[(dodecylthiocarbonyl)-methyl]-glutarimide (DTCM-G), and dehydroxymethylepoxyquinomicin (DHMEQ) groups. ${ }^{* *} \mathrm{P}<0.001 ;{ }^{* * *} \mathrm{P}<0.0001$.
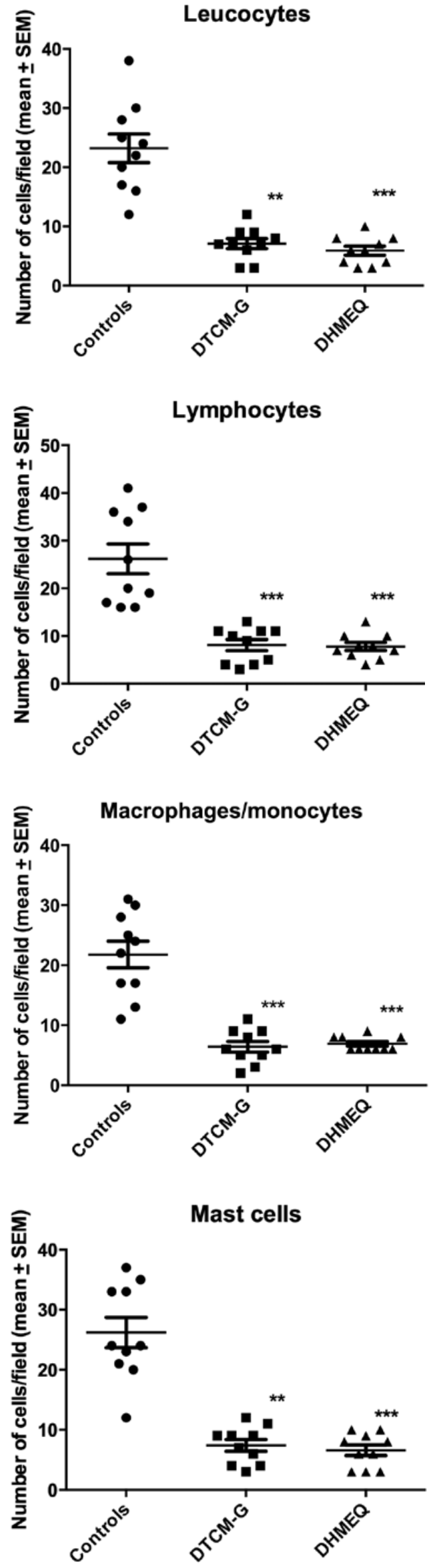

Figure 5. Submucosal densities of immune cells in the control, 3-[(dodecylthiocarbonyl)-methyl]-glutarimide (DTCM-G), and dehydroxymethylepoxyquinomicin (DHMEQ) groups. ${ }^{* *} \mathrm{P}<0.001 ;{ }^{* * * *} \mathrm{P}<0.0001$. 

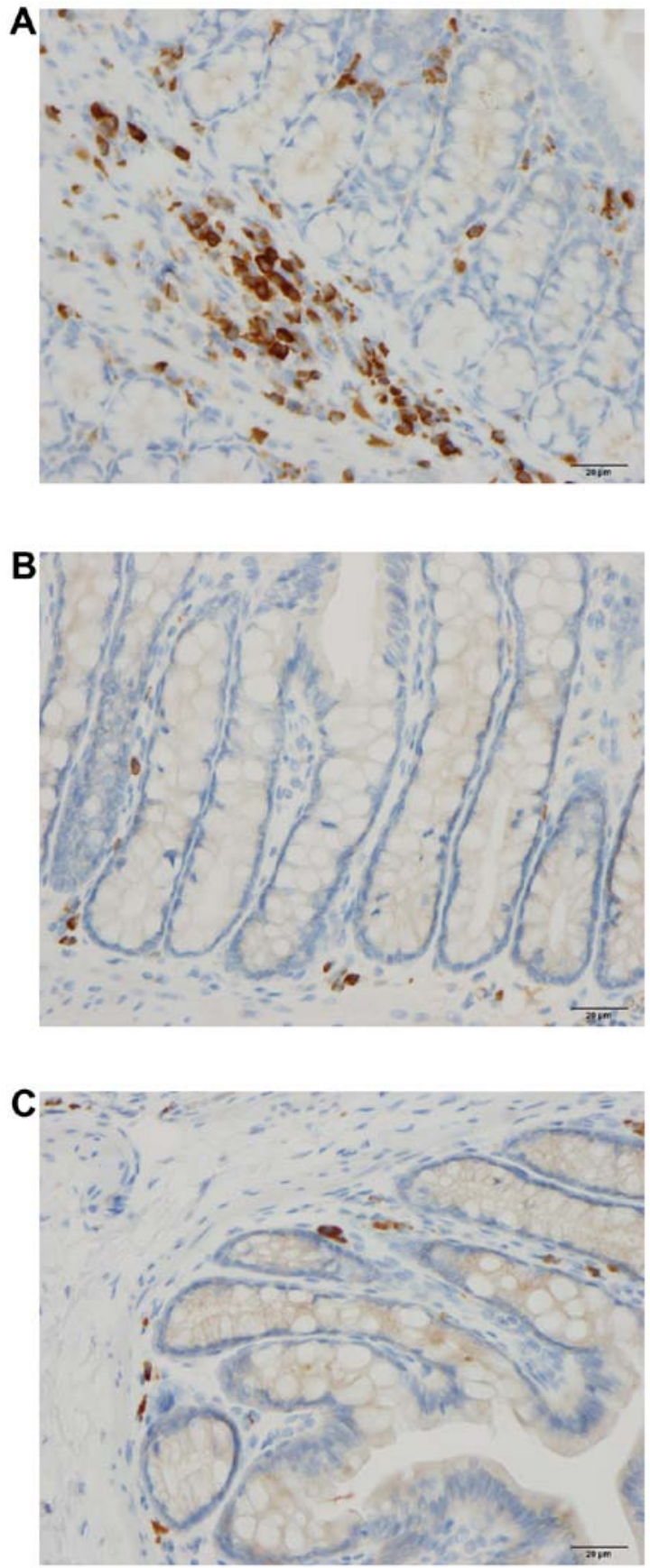

Figure 6. Submucosal leukocytes in (A) a control rat, (B) a 3-[(dodecylthiocarbonyl)-methyl]-glutarimide (DTCM-G)-treated rat, and (C) a dehydroxymethylepoxyquinomicin (DHMEQ)-treated rat.

Wallis test was significant at $\mathrm{P}<0.0001)$. The densities of macrophages/monocytes in the submucosa were significantly lower in the DTCM-G- and DHMEQ-treated animals than in the control animals $(\mathrm{P}<0.0001$ for both).

The densities of mast cells in the submucosa of the control, DTCM-G and DHMEQ groups were $26.2 \pm 5.1,7.4 \pm 1.0$ and $6.6 \pm 0.9$ cells/field (Figs. 5 and 9). There were significant differences between the 3 groups, as revealed by the KruskalWallis test. The densities of mast cells in the submucosa were significantly lower in the DTCM-G- and DHMEQ-treated animals than in the control animals $(\mathrm{P}<0.001$ and $\mathrm{P}<0.0001$, respectively).
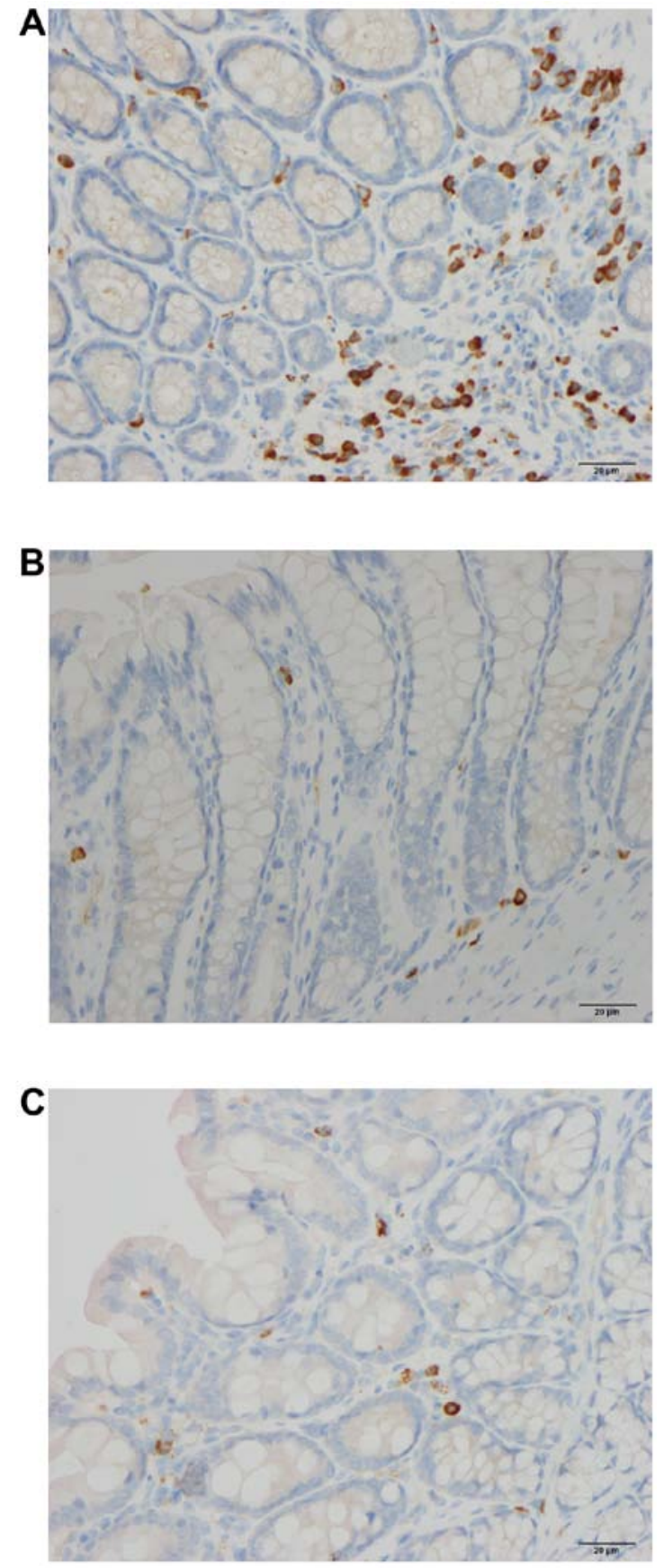

Figure 7. Lymphocytes in the mucosa of (A) a control rat, (B) a 3-[(dodecylthiocarbonyl)-methyl]-glutarimide (DTCM-G)-treated rat, and (C) a dehydroxymethylepoxyquinomicin (DHMEQ)-treated rat.

\section{Discussion}

DSS-induced colitis closely mimics human UC and is a useful model for studying the inflammatory/recovery processes and for testing potential therapies (31). Similar to human UC, the animals suffer from diarrhea and rectal bleeding. The colitis induced by DSS is caused by a chemical injury to the intestinal epithelium, which results in the exposure of the lamina propria and the submucosa to luminal antigens and enteric bacteria, triggering inflammation (32). However, one limitation of this animal model is that it lacks the chronic changes seen in human UC (32). 

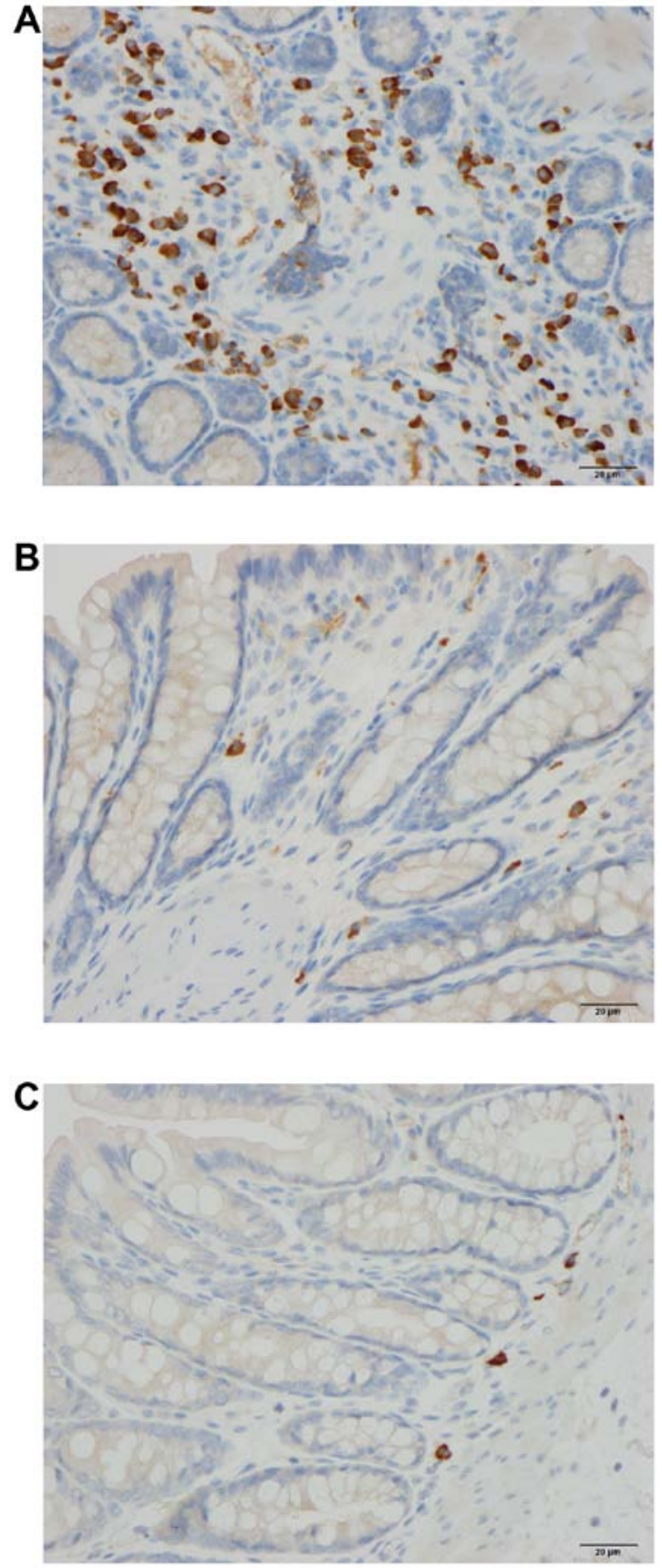

Figure 8. Submucosal macrophages/monocytes in (A) a control rat, (B) a 3-[(dodecylthiocarbonyl)-methyl]-glutarimide (DTCM-G)-treated rat, and (C) a dehydroxymethylepoxyquinomicin (DHMEQ)-treated rat.

DTCM-G and DHMEQ are novel anti-inflammatory agents with different modes of action: DTCM-G is an AP-1 inhibitor that inhibits the activation of macrophages and proinflammatory cytokines $(22,33)$, while DHMEQ inhibits the nuclear translocation of NF- $\mathrm{KB}$ by binding to the Rel-family components and inhibiting their DNA-binding activity (34-36). The migration of immune cells to the site of inflammation, and their subsequent activation are regulated by different cytokines and chemokines, which in turn are regulated by the transcription factors, AP-1 and NF-kB (37-39). DTCM-G and DHMEQ have been found to have a high potency for suppressing inflammation in animal models of various inflammatory diseases including $\operatorname{IBD}(23,24)$.
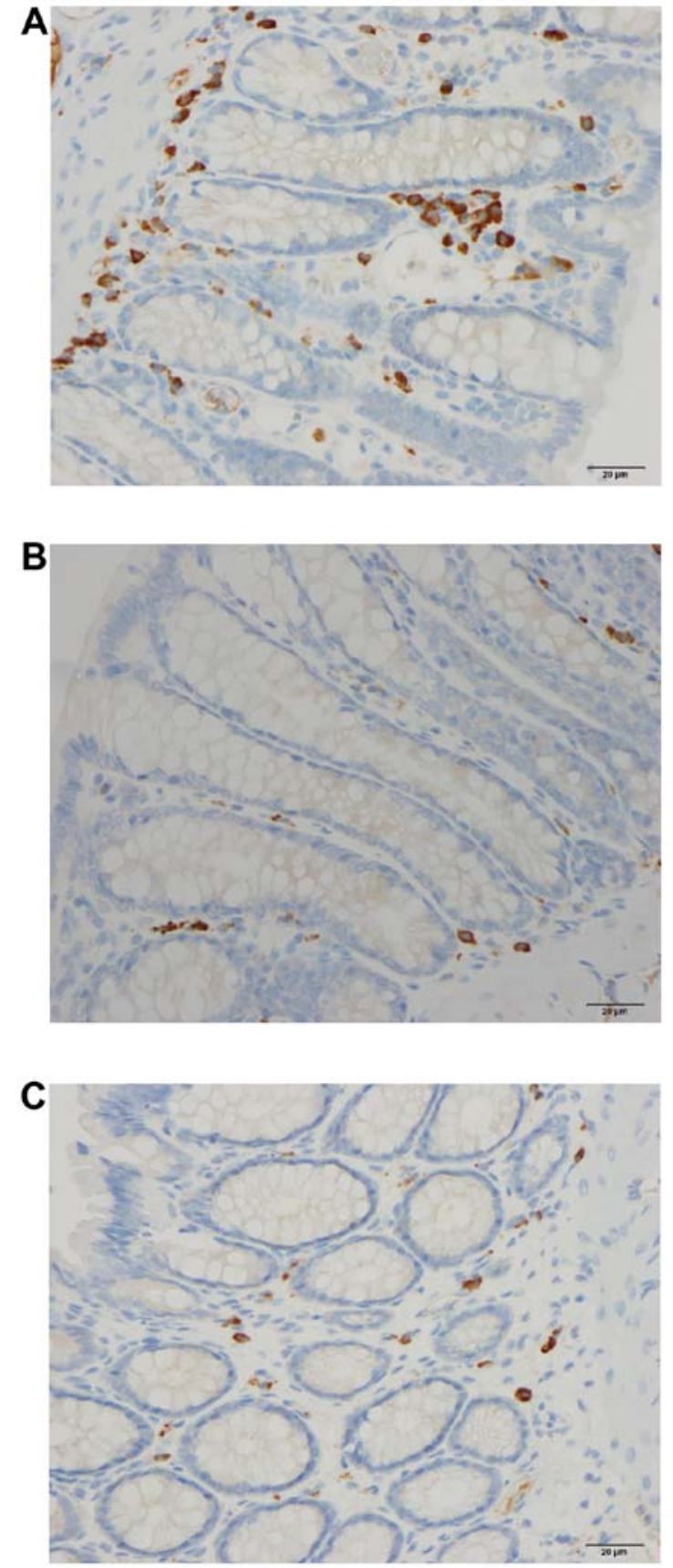

Figure 9. Submucosal density of mast cells in (A) a control rat, (B) a 3-[(dodecylthiocarbonyl)-methyl]-glutarimide (DTCM-G)-treated rat, and (C) a dehydroxymethylepoxyquinomicin (DHMEQ)-treated rat.

In the present study, 5 days of treatment with either DTCM-G or DHMEQ reduced the inflammation observed in the rats with DSS-induced colitis, as indicated by the reduction in the DAI values, the histological grading score for colitis, and the infiltration of immune cells in the animals treated with these 2 agents compared to their vehicle-treated, control counterparts. These observations are in line with the previously reported effects of DHMEQ in a murine model of (DSS-induced) colitis, whereby pro-inflammatory cytokines such as interleukin (IL)- $1 \beta, \mathrm{TNF} \alpha$, IL-6, IL-12p40, IL-17 and monocyte chemotactic protein-1 were suppressed following the administration of DHMEQ (23).

In addition to its anti-inflammatory effects, the administration of DHMEQ either i.p. or intravenously does not result in a 
detectable concentration in the blood; although there is a high concentration in the peritoneal cavity within 5 min following the i.p. administration of DHMEQ, and a rapid decrease $30 \mathrm{~min}$ thereafter, the drug cannot be detected in the bloodstream (34). Umezawa has proposed that DHMEQ exerts its effects locally via DHMEQ uptake by immune cells in the peritoneal cavity prior to their migration to sites of inflammation (34). This may explain the low toxicity of this agent observed in experimental animals.

There is considerable concern regarding the use of azathioprine and anti-TNF $\alpha$ antibodies, which are used in the clinical setting for the treatment of IBD, due to the possible increased risk of developing cancer when they are used on a long-term basis $(3,4,11,12)$. By contrast, both DTCM-G and DHMEQ exhibit anticancer activities against various types of cancers (40-49). The demonstrated anti-inflammatory and anticancer effects of DTCM-G and DHMEQ, and the absence of any apparent associated toxicity render them excellent therapeutic candidates for clinical use in the treatment of IBD.

\section{Acknowledgements}

The study was supported by grants from Helse-Vest (grant no. 911978) and Helse-Fonna (grant no. 40415).

\section{References}

1. Prantera $\mathrm{C}$ and Marconi S: Glucocorticosteroids in the treatment of inflammatory bowel disease and approaches to minimizing systemic activity. Therap Adv Gastroenterol 6: 137-156, 2013.

2. Cosnes J, Gower-Rousseau C, Seksik P and Cortot A: Epidemiology and natural history of inflammatory bowel diseases. Gastroenterology 140: 1785-1794, 2011.

3. Carter MJ, Lobo AJ and Travis SP; IBD Section, British Society of Gastroenterology: Guidelines for the management of inflammatory bowel disease in adults. Gut 53 (Suppl 5): V1-V16, 2004.

4. Podolsky DK: Inflammatory bowel disease. N Engl J Med 347: 417-429, 2002

5. Podolsky DK: The current future understanding of inflammatory bowel disease. Best Pract Res Clin Gastroenterol 16: 933-943, 2002.

6. Loftus EV Jr: Clinical epidemiology of inflammatory bowel disease: Incidence, prevalence, and environmental influences. Gastroenterology 126: 1504-1517, 2004

7. Loftus EV Jr and Sandborn WJ: Epidemiology of inflammatory bowel disease. Gastroenterol Clin North Am 31: 1-20, 2002.

8. Betteridge JD, Armbruster SP, Maydonovitch C and Veerappan GR: Inflammatory bowel disease prevalence by age, gender, race, and geographic location in the U.S. military health care population. Inflamm Bowel Dis 19: 1421-1427, 2013.

9. Yang SK, Loftus EV Jr and Sandborn WJ: Epidemiology of inflammatory bowel disease in Asia. Inflamm Bowel Dis 7 : 260-270, 2001.

10. Goh K and Xiao SD: Inflammatory bowel disease: A survey of the epidemiology in Asia. J Dig Dis 10: 1-6, 2009.

11. Sands BE: New therapies for the treatment of inflammatory bowel disease. Surg Clin North Am 86: 1045-1064, 2006.

12. Sands BE: The risks and benefits of early immunosuppression and biological therapy. Dig Dis 30 (Suppl 3): 100-106, 2012.

13. Prantera C, Pallone F, Brunetti G, Cottone M and Miglioli M; The Italian IBD Study Group: Oral 5-aminosalicylic acid (Asacol) in the maintenance treatment of Crohn's disease. Gastroenterology 103: 363-368, 1992.

14. Lopez A, Billioud V, Peyrin-Biroulet C and Peyrin-Biroulet L: Adherence to anti-TNF therapy in inflammatory bowel diseases: A systematic review. Inflamm Bowel Dis 19: 1528-1533, 2013.

15. Danese S: Anti TNF-alpha treatment for Crohn' disease: 'ménage a trois'. Curr Drug Targets 11: 136-137, 2010.

16. Danese $\mathrm{S}$ and Angelucci E: New and emerging biologics in the treatment of inflammatory bowel disease: Quo vadis? Gastroenterol Clin Biol 33 (Suppl 3): S217-S227, 2009.
17. Danese S, Angelucci E, Malesci A and Caprilli R: Biological agents for ulcerative colitis: Hypes and hopes. Med Res Rev 28: 201-218, 2008.

18. Danese S, Colombel JF, Peyrin-Biroulet L, Rutgeerts P and Reinisch W: Review article: The role of anti-TNF in the management of ulcerative colitis - past, present and future. Aliment Pharmacol Ther 37: 855-866, 2013.

19. Danese S, Colombel JF, Reinisch W and Rutgeerts PJ: Review article: Infliximab for Crohn's disease treatment - shifting therapeutic strategies after 10 years of clinical experience. Aliment Pharmacol Ther 33: 857-869, 2011.

20. Danese S, Semeraro S, Armuzzi A, Papa A and Gasbarrini A: Biological therapies for inflammatory bowel disease: Research drives clinics. Mini Rev Med Chem 6: 771-784, 2006.

21. Ota E, Takeiri M, Tachibana M, Ishikawa Y, Umezawa K and Nishiyama S: Synthesis and biological evaluation of molecular probes based on the 9-methylstreptimidone derivative DTCMglutarimide. Bioorg Med Chem Lett 22: 164-167, 2012.

22. Shibasaki S, Yamashita K, Goto R, Wakayama K, Tsunetoshi Y, Zaitsu M, Igarashi R, Haga S, Ozaki M, Umezawa K and Todo S: Immunosuppressive effects of DTCM-G, a novel inhibitor of the mTOR downstream signaling pathway. Transplantation 95: 542-550, 2013

23. Funakoshi T, Yamashita K, Ichikawa N, Fukai M, Suzuki T, Goto R, Oura T, Kobayashi N, Katsurada T, Ichihara S, et al: A novel NF- $\mathrm{KB}$ inhibitor, dehydroxymethylepoxyquinomicin, ameliorates inflammatory colonic injury in mice. J Crohn's Colitis 6: 215-225, 2012.

24. El-Salhy M,Umezawa K, Gilja OH,Hatlebakk JG, Gundersen Dand Hausken T: Amelioration of severe TNBS induced colitis by novel AP-1 and NF- $\kappa$ B inhibitors in rats. ScientificWorldJournal 2014: 813804, 2014.

25. Elson CO, Sartor RB, Tennyson GS and Riddell RH: Experimental models of inflammatory bowel disease. Gastroenterology 109: 1344-1367, 1995.

26. Matsumoto N, Ariga A, To-e S, Nakamura H, Agata N, Hirano S, Inoue $\mathbf{J}$ and Umezawa $\mathrm{K}$ : Synthesis of NF-kappaB activation inhibitors derived from epoxyquinomicin C. Bioorg Med Chem Lett 10: 865-869, 2000.

27. Grimstad T, Bjørndal B, Cacabelos D, Aasprong OG, Omdal R, Svardal A, Bohov P, Pamplona R, Portero-Otin M, Berge RK and Hausken T: A salmon peptide diet alleviates experimental colitis as compared with fish oil. J Nutr Sci 2: e2, 2013.

28. Stucchi AF, Shofer S, Leeman S, Materne O, Beer E, McClung J, Shebani K, Moore F, O'Brien M and Becker JM: NK-1 antagonist reduces colonic inflammation and oxidative stress in dextran sulfate-induced colitis in rats. Am J Physiol Gastrointest Liver Physiol 279: G1298-G1306, 2000.

29. Cooper HS, Murthy SN, Shah RS and Sedergran DJ: Clinicopathologic study of dextran sulfate sodium experimental murine colitis. Lab Invest 69: 238-249, 1993.

30. Mao JW, Huang YS, Tang HY, Bi J, Liu YF and Wang YD: Flt3/Flt3L participates in the process of regulating dendritic cells and regulatory T cells in DSS-induced colitis. Gastroenterol Res Pract 2014: 483578, 2014.

31. Dieleman LA, Palmen MJ, Akol H, Bloemena E, Peña AS, Meuwissen SG and Van Rees EP: Chronic experimental colitis induced by dextran sulphate sodium (DSS) is characterized by Th1 and Th2 cytokines. Clin Exp Immunol 114: 385-391, 1998.

32. Low D, Nguyen DD and Mizoguchi E: Animal models of ulcerative colitis and their application in drug research. Drug Des Devel Ther 7: 1341-1357, 2013.

33. Takeiri M, Tachibana M,Kaneda A, Ito A, Ishikawa Y,Nishiyama S, Goto R, Yamashita K, Shibasaki S, Hirokata G, et al: Inhibition of macrophage activation and suppression of graft rejection by DTCM-glutarimide, a novel piperidine derived from the antibiotic 9-methylstreptimidone. Inflamm Res 60: 879-888, 2011.

34. Umezawa K: Possible role of peritoneal NF- $\mathrm{B}$ B in peripheral inflammation and cancer: Lessons from the inhibitor DHMEQ. Biomed Pharmacother 65: 252-259, 2011.

35. Yamamoto M, Horie R, Takeiri M, Kozawa I and Umezawa K: Inactivation of NF-kappaB components by covalent binding of (-)-dehydroxymethylepoxyquinomicin to specific cysteine residues. J Med Chem 51: 5780-5788, 2008.

36. Ariga A, Namekawa J, Matsumoto $\mathrm{N}$, Inoue $\mathrm{J}$ and Umezawa $\mathrm{K}$ : Inhibition of tumor necrosis factor-alpha-induced nuclear translocation and activation of NF-kappa B by dehydroxymethylepoxyquinomicin. J Biol Chem 277: 24625-24630, 2002.

37. Schonthaler HB, Guinea-Viniegra $J$ and Wagner EF: Targeting inflammation by modulating the Jun/AP-1 pathway. Ann Rheum Dis 70 (Suppl 1): i109-i112, 2011. 
38. Matsushima A, Kaisho T, Rennert PD, Nakano H, Kurosawa K, Uchida D, Takeda K, Akira S and Matsumoto M: Essential role of nuclear factor (NF)-kappaB-inducing kinase and inhibitor of kappaB (IkappaB) kinase alpha in NF-kappaB activation through lymphotoxin beta receptor, but not through tumor necrosis factor receptor I. J Exp Med 193: 631-636, 2001.

39. Umezawa K, Ariga A and Matsumoto N: Naturally occurring and synthetic inhibitors of NF-kappaB functions. Anticancer Drug Des 15: 239-244, 2000

40. Brassesco MS, Roberto GM, Morales AG, Oliveira JC, Delsin LE, Pezuk JA, Valera ET, Carlotti CG Jr, Rego EM, de Oliveira HF, et al: Inhibition of NF- $\kappa \mathrm{B}$ by dehydroxymethylepoxyquinomicin suppresses invasion and synergistically potentiates temozolomide and $\gamma$-radiation cytotoxicity in glioblastoma cells. Chemother Res Pract 2013: 593020, 2013.

41. Celegato $M$, Borghese $C$, Umezawa $K$, Casagrande $N$, Colombatti A, Carbone A and Aldinucci D: The NF- $\mathrm{KB}$ inhibitor DHMEQ decreases survival factors, overcomes the protective activity of microenvironment and synergizes with chemotherapy agents in classical Hodgkin lymphoma. Cancer Lett 349: 26-34, 2014.

42. Fukushima T, Kawaguchi M, Yorita K, Tanaka H, Takeshima H, Umezawa $\mathrm{K}$ and Kataoka $\mathrm{H}$ : Antitumor effect of dehydroxymethylepoxyquinomicin, a small molecule inhibitor of nuclear factor- $\kappa \mathrm{B}$, on glioblastoma. Neuro-oncol 14: 19-28, 2012.

43. Kozakai N,Kikuchi E,Hasegawa M, Suzuki E, Ide H, Miyajima A, Horiguchi Y, Nakashima J, Umezawa K, Shigematsu N and Oya M: Enhancement of radiosensitivity by a unique novel NF- $\kappa$ B inhibitor, DHMEQ, in prostate cancer. Br J Cancer 107: 652-657, 2012
44. Lampiasi N, Azzolina A, Umezawa K, Montalto G, McCubrey JA and Cervello M: The novel NF- $\mathrm{BB}$ inhibitor DHMEQ synergizes with celecoxib to exert antitumor effects on human liver cancer cells by a ROS-dependent mechanism. Cancer Lett 322: 35-44, 2012.

45. Lampiasi N, Umezawa K, Montalto G and Cervello M: Poly (ADP-ribose) polymerase inhibition synergizes with the NF- $\mathrm{BB}$ inhibitor DHMEQ to kill hepatocellular carcinoma cells. Biochim Biophys Acta 1843: 2662-2673, 2014.

46. Miyanishi N, Suzuki Y, Simizu S, Kuwabara Y, Banno K and Umezawa K: Involvement of autocrine CXCL12/CXCR4 system in the regulation of ovarian carcinoma cell invasion. Biochem Biophys Res Commun 403: 154-159, 2010.

47. Mino K, Ozaki M, Nakanishi K, Haga S, Sato M, Kina M, Takahashi M, Takahashi N, Kataoka A, Yanagihara K, et al: Inhibition of nuclear factor-kappaB suppresses peritoneal dissemination of gastric cancer by blocking cancer cell adhesion. Cancer Sci 102: 1052-1058, 2011.

48. Suzuki K, Aiura K, Matsuda S, Itano O, Takeuchi O, Umezawa K and Kitagawa Y: Combined effect of dehydroxymethylepoxyquinomicin and gemcitabine in a mouse model of liver metastasis of pancreatic cancer. Clin Exp Metastasis 30: 381-392, 2013.

49. Yasuda A, Kondo S, Nagumo T, Tsukamoto H, Mukudai Y, Umezawa K and Shintani S: Anti-tumor activity of dehydroxymethylepoxyquinomicin against human oral squamous cell carcinoma cell lines in vitro and in vivo. Oral Oncol 47: 334-339, 2011. 